\title{
A Natural Occurring Mouse Model with Adgrv1 Mutation of Usher Syndrome 2C and Characterization of its Recombinant Inbred Strains
}

\author{
Weiming Yan ${ }^{\mathrm{a}}$ Pan Long ${ }^{\mathrm{a}}$ Tao Chen ${ }^{\mathrm{a}}$ Wei Liu ${ }^{\mathrm{b}}$ Lu Yao $^{\mathrm{a}}$ Ze Ren ${ }^{\mathrm{a}}$ \\ Xiangqian $\mathrm{Li}^{\mathrm{a}}$ Jiancong Wang ${ }^{\mathrm{c}}$ Junhui Xue ${ }^{\mathrm{a}}$ Ye Tao $^{\mathrm{d}}$ Lei Zhang ${ }^{\mathrm{a}}$ \\ Zuoming Zhanga
}

\begin{abstract}
aDepartment of Clinical Medicine, Faculty of Aerospace Medicine, Key Laboratory of Aerospace Medicine of the National Education Ministry, The Fourth Military Medical University, Xi'an, bMedical Experiment Center, Shaanxi University of Chinese Medicine, Shiji Ave., Xi'an-Xianyang New Economic Zone, Xi'an, 'BeiJing HealthOLight Technology Co., Ltd, 'Department of Ophthalmology, General Hospital of the People's Liberation Army, Ophthalmology \& Visual Science Key Lab of PLA, Beijing, China
\end{abstract}

\section{Key Words}

Retinitis pigmentosa - Usher syndrome Electroretinogram • Auditory brainstem response • Inbred strain $\cdot$ Mutation

\begin{abstract}
Background/Aims: Our laboratory discovered a Kunming mouse with enormous electroretinogram (ERG) defects. Its auditory brainstem response (ABR) threshold was significantly elevated and closely resembled the features of Usher syndrome (USH). This study sought to cross these USH-like mice (named KM ${ }^{\text {ush/ush }}$ mice) with CBA/CaJ mice to establish recombinant inbred strains and identify their phenotypes and genotypes. Methods: KM ${ }^{\text {ush/ush }}$ mice were crossed with $\mathrm{CBA} / \mathrm{CaJ}$ mice to establish inbred strains by sibling mating. ERG, $A B R$, ocular fundus morphology, histological examinations of the retina and inner ear, quantitative real-time polymerase chain reaction, western blotting, and exon sequencing were performed to assess the phenotypes and genotypes of the offspring strains. Results: The F1 hybrids from crossing $\mathrm{KM}^{\text {ush/ush }}$ and $\mathrm{CBA} / \mathrm{CaJ}$ mice had normal ERG and $\mathrm{ABR}$ responses. The F2 offspring from intercrossing the F1 mice showed a segregation of the retinitis pigmentosa (RP) and hearing loss phenotypes. The CBA-1 ${ }^{\text {ush/ush }}$ mice had an RP phenotype that was characterized by a vanished ERG waveform and loss of the outer nuclear layer. Their Pde6b gene had a nonsense mutation that resulted in the failure of protein production in western blotting. However, the $A B R$ threshold of this strain of mice was normal. The CBA-2 ${ }^{\text {ush/ush }}$ mice had normal retinal function and architecture. Their ABR threshold was increased, with a dramatic degeneration of the stereocilia bundles in the outer hair cells of the inner ear. Whole exome sequencing and exon sequencing revealed a deletion of one base pair in exon 31 of the Adgrv1 gene, which

W. Yan, P. Long, T. Chen and W. Liu contributed equally to this work.

Dr. Zuoming Zhang,

Dr. Junhui Xue,

Dr. Ye Tao, Dr. Lei Zhang

KARGER

Dept. of Clinical Medicine, Faculty of Aerospace Medicine, Key Laboratory of Aerospace Medicine of the National Education Ministry, The Fourth Military Medical University, Xi'an, 710032 (China); E-Mail zhangzm@fmmu.edu.cn/xuejunhui@fmmu.edu.cn/toy1011@163.com/ sanshizhanglei@163.com
\end{abstract}


would result in the premature termination of protein encoding. The level of Adgrv1 mRNA was reduced in the CBA-2 $2^{\text {ush/ush }}$ mice. The CBA-3 $3^{\text {ush/ush }}$ mice had phenotypes of RP, elevated ABR threshold, and degeneration of the stereocilia bundles in the outer hair cells. They were closely associated with the nonsense mutations of Pde6b and Adgrv1, respectively. Conclusion: We isolated a mouse strain with hearing loss from inbred mice with retinal degeneration and established it as a recombinant inbred strain with a spontaneous mutation in Adgrv1, the human Usher syndrome $2 \mathrm{C}$ gene. The retinal degeneration was cause by a mutation in Pde6b, while the hearing loss was caused by a mutation in Adgrv1.

(C) 2018 The Author(s)

Published by S. Karger AG, Basel

\section{Introduction}

Retinitis pigmentosa (RP) is a group of common inherited retinal diseases with high heterogeneity [1]. Most of the RP phenotypes are confined to the eyes and could eventually lead to blindness. These types of RP are defined as non-syndromic RP [2]. By contrast, types of RP with extraocular lesions are defined as syndromic RP, of which the most prevalent form is Usher syndrome (USH) [3]. USH is an autosomal recessive genetic disorder characterized by RP and deafness. USH can be divided into three subtypes according to onset time, degree of deafness, and the occurrence of vestibular dysfunction [4]. Type 2 USH (USH2) is the most prevalent form of USH, with moderate-to-severe sensorineural hearing loss, RP, and preserved vestibular function [5]. Similar to RP, USH is a clinically heterogeneous disorder [6]. With the development of family linkage analysis and DNA sequencing techniques, several genes have been shown to be associated with the development of USH [7], including Myo 7a, Ush1c, Cdh23, Pcdh15, Ush1g, Ush2a, Adgrv1, Dfnb31, and Clrn1 [8, 9]. A mutation in any one of these genes can give rise to USH $[10,11]$. The complex pathogenesis of USH necessitates the continued exploration for well-characterized animal models to develop therapeutic strategies [12]. To date, approximately 40 different USH mouse models have been discovered by the Jackson Laboratory [13]. In greater detail, four of the five USH2 mouse models have been generated by transgenic insertion or intergenic deletion [14].

Our laboratory previously discovered a mouse with RP and deafness under the Kunming (KM) background (named $\mathrm{KM}^{\text {ush/ush}}$ ). The $\mathrm{KM}^{\text {ush/ush }}$ mouse strain has been inbred for 38 generations through sibling mating [15]. It was reported that a mutated Pde6b gene causes RP [16], while a mutated Ush2a gene contributes to USH2A [17]. In this regard, we examined Pde6b and Ush2a mRNA levels in $\mathrm{KM}^{\text {ush/ush }}$ mice, and found they were both expressed relatively lower than in wild-type KM mice [15]. Furthermore, we verified the presence of a nonsense mutation in Pde6b and several missense mutations in Ush2a in the $\mathrm{KM}^{\text {ush/ush }}$ mice (data unpublished). Therefore, the mutated Pde6b and Ush2a genes were previously assumed to be responsible for the RP and hearing loss phenotypes of $\mathrm{KM}^{\text {ush}} / \mathrm{ush}$ mice, respectively [15].

Nonsense mutations of $P d e 6 b$ are reported to result in the downregulation of its mRNA and eventually the development of RP [18]. The mutation types of Ush2a in human USH2A usually include at least one nonsense mutation $[19,20]$. However, humans with nonsyndromic RP and normal hearing ability tend to carry only a missense mutation of Ush2a $[21,22]$. In this sense, how the missense mutations of Ush2a alone in $\mathrm{KM}^{\text {ush }}$ ush mice led to a reduction in its mRNA level and the abnormal hearing phenotype remained unknown.

On the basis of the above findings, we hypothesized that the missense mutations of Ush $2 a$ might not act as the causative factor for the hearing loss in $\mathrm{KM}^{\text {ush }} / \mathrm{ush}$ mice. Therefore, this study sought to identify the reason for the hearing loss in $\mathrm{KM}^{\text {ush }} /$ ush mice. As KM mice are an outbred colony and their hearing ability declines with age [23], we crossed $\mathrm{KM}^{\text {ush/ush }}$ mice with $\mathrm{CBA} / \mathrm{CaJ}$ mice. $\mathrm{CBA} / \mathrm{CaJ}$ mice are a wild-type inbred strain that is commonly used in researches on hearing [24]. This strain retains normal hearing well beyond 1 year of age $[25,26]$. The intercrossing sought to exclude the impact of age on hearing ability and to pass the mutated genes into the CBA/CaJ background. Further intercrossing of the F1 hybrids led to the segregation of the RP and hearing loss phenotypes in the F2 offspring. In the present

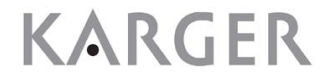


Yan et al.: Natural Occurring Mouse Model with Adgrv1 Mutation

study, all of these recombinant offspring strains with inherited RP and/or hearing loss were subjected to phenotype and genotype analyses, which would help to elucidate the genetic mechanisms underlying RP/USH. Besides, the establishment of a recombined inbred strain with a spontaneous mutation in Adgrv1 gene of human USH2C could function as an effective tool for future therapeutic experiments.

\section{Materials and Methods}

\section{Animal rearing}

KM mice were obtained from the Laboratory Animal Center of the Fourth Military Medical University (License No. \#2014270138S, Xi'an, China). CBA/CaJ mice (\#000654) were purchased from the Jackson Laboratory (Bar Harbor, ME, USA). KM ${ }^{\text {ush/ush }}$ mice and rd1 mice (a typical mouse model for RP) [27] were obtained from the SPF animal facility of the Aerospace Clinical Medicine Department of the Fourth Military Medical University (License No. \#SYXK2012-004). All animals were housed and handled in accordance with the Association for Research in Vision and Ophthalmology Statement Use of Animals in Ophthalmic and Vision Research, and were approved by the Animal Care and Use Committee of the Fourth Military Medical University.

\section{Experimental design}

Pedigree analysis of offspring from crossing $K M^{\text {ush/ush }}$ mice with CBA/CaJ mice. Two female CBA/CaJ mice were chosen to mate with two male $\mathrm{KM}^{\text {ush }}{ }^{\text {ush }}$ mice to generate F1 hybrids. Sibling mating of the F1 hybrids was used to produce the F2 offspring. Mice from every generation were subjected to electroretinogram (ERG) and auditory brainstem response (ABR) examinations on postnatal day 21 (P21). F2 offspring with identical ERG and ABR phenotypes were inbred through sibling mating, and named as CBA-1 ${ }^{\text {ush }}$ /sh mice (mice with reduced ERG amplitudes and normal ABR threshold that was below $50 \mathrm{~dB}$ ), CBA-2 ${ }^{\text {ush }} /$ sh mice (with elevated ABR threshold and normal ERG amplitudes), CBA-3 ${ }^{\text {ush/ush }}$ mice (with reduced ERG amplitudes and elevated ABR threshold), and CBA mice (with normal ERG amplitudes and ABR threshold). The offspring of each strain were also screened by ERG and ABR. Offspring with phenotypes that were consistent with their parental generation underwent sibling mating.

Characterization of the phenotypes and genotypes of CBA-1 ush/ush mice. At P21, CBA-1 $1^{\text {ush/ush }}$ and $\mathrm{KM}^{\text {ush }} / \mathrm{ush}$ mice were selected randomly for the characterization of their phenotypes and genotypes. Agematched CBA/CaJ and KM mice served as controls. Fundus imaging, optical coherence tomography (OCT), and fundus fluorescein angiography (FFA) were performed for morphological observations. Retinal sections were stained with hematoxylin-eosin (HE) for histological examinations. Exon sequencing of Pde6b in tail tissue and western blotting of PDE6B in retinal tissue were performed to explore the genotype.

Characterization of the phenotypes and genotypes of CBA-2 $2^{\text {ush } / \text { ush }}$ mice. CBA-2 $2^{\text {ush } / \text { sh }}$ mice were randomly selected at P14, P21, and P56. Age-matched CBA/CaJ mice served as controls. ERG and ABR examinations were conducted. Fundus imaging, FFA, retinal OCT scanning, and retinal sections with HE staining were also performed for ocular morphological observations. The thickness of the outer nuclear layer (ONL) in the retinal sections was measured. Observation of cochlear cross sections with HE staining and scanning electron microscopy were performed to examine the structure of the inner ear at P56. Whole exome sequencing was conducted in tail tissue to identify the causative gene for the hearing loss in the F3, F6 offspring from CBA$2^{\text {ush } / \text { ssh }}$ mice and $\mathrm{KM}^{\text {ush/ush }}$ mice at P21. Adgrv1 exon sequencing was performed at P21 using tail tissue of F2 offspring from intercrossing $\mathrm{CBA}-2^{\text {ush } / \text { ush }}$ mice with $\mathrm{CBA} / \mathrm{CaJ}$ mice. Additionally, quantitative real-time polymerase chain reaction (qRT-PCR) analysis was performed to quantify the retinal levels of Ush2a and Adgrv1 mRNA in CBA/CaJ, CBA-2 ${ }^{\text {ush } / \text { ush }}, \mathrm{KM}^{\text {ush/ush }}$, and rd1 mice at P21.

Characterization of the phenotypes and genotypes of CBA-3 $3^{\text {ush } / \text { sh }}$ mice. Fundus imaging, OCT of the retina, FFA, and HE staining of retinal sections were conducted in CBA-3 $3^{\text {ush/ush }}$ mice at P21. Age-matched $\mathrm{CBA} / \mathrm{CaJ}$ mice served as controls. Exon sequencing was performed using tail tissue from CBA-3 ush/ush mice at P21 to detect the mutation of Pde6b and to verify the underlying reason for the ocular phenotypes. Western blotting was conducted to quantify the level of PDE6B in the retina. Cochlear cross sections and electron microscopy scanning were performed to examine the morphology of the inner ear at P56. Exon sequencing was conducted to detect the mutation of Adgrv1 in tail tissue to verify the underlying reason for the hearing loss.

\section{KARGER}




\section{Cellular Physiology Cell Physiol Biochem 2018;47:1883-1897 \begin{tabular}{l|l} 
and Biochemistry Published online:June 29, 2018 & $\begin{array}{l}\text { (c) 2018 The Author(s). Published by S. Karger AG, Basel } \\
\text { www.karger.com/cpb }\end{array}$ \\
\hline
\end{tabular}}

Yan et al.: Natural Occurring Mouse Model with Adgrv1 Mutation

\section{Experimental techniques}

Fundus imaging, OCT, and FFA. The animals were anesthetized with an intraperitoneal injection of $1 \%$ sodium pentobarbital ( $3 \mathrm{~mL} / \mathrm{kg}$; Sigma-Aldrich, Burlington, MA, USA) and Sumianxin II (a compound solution of xylidinothiazoline, EDTA, dihydroetorphine hydrochloride, and haloperidol, $0.025 \mathrm{~mL} / \mathrm{kg}$; Jilin Shengda Animal Pharmaceutical Co., Ltd., Dunhua, China), and were fixed on a platform. The pupil was dilated with a drop of $0.5 \%$ tropicamide-phenylephrine ophthalmic solution (Shenyang Xingji Corporation, Shenyang, China). The cornea was covered with sodium hyaluronate gel (Bausch \& Lomb Freda, Jinan, China) and was attached to the camera lens of a Retinal Imaging System (OPTO-RIS; OptoProbe, Burnaby, Canada) for fundus and FFA imaging or 4D-ISOCT Microscope Imaging System (ISOCT; OptoProbe) for the retinas. Subsequently, fundus or OCT images were taken with the optic nerve head centered on the corresponding box by altering the position and angle of the mice. As for FFA, 20\% sodium fluorescein (Guangzhou Baiyunshan Mingxing Pharmaceutical Co., Ltd., Guangzhou, China) at a dose of $10 \mathrm{~mL} / \mathrm{kg}$ was injected intraperitoneally and images were captured after $2 \mathrm{~min}$. The injected sodium fluorescein was completely excreted after $24 \mathrm{~h}$.

$E R G$ and $A B R$ recordings. ERG recording was performed as reported previously [27]. Briefly, the mice were anesthetized deeply after overnight dark adaption and their pupils were dilated with a $0.5 \%$ tropicamide-phenylephrine ophthalmic solution. The active electrode was placed on the cornea. The reference electrode and ground electrode were inserted beneath the skin of the cheek around the tested eye and tail, respectively. Full-field (Ganzfeld) stimulation and a computer system (RETI port; Roland, Germany) were utilized to record the ERG responses. All operations were conducted under a dim red light to maximize retinal sensitivity according to the guidelines of the International Society for Clinical Electrophysiology of Vision [28].

After ERG recording, the experimental animals were subjected to auditory function assessment in a sound-attenuating room using an ABR Workstation (Otometrics, Taastrup, Denmark) as described previously [15]. The active, reference, and ground electrodes were placed subcutaneously in the vertex auricle of the tested ears and tail, respectively. ABR waves were recorded in response to a series of click stimuli. The stimuli were presented initially at $95 \mathrm{~dB}$ sound pressure level (SPL). Then, the SPL was reduced progressively by $5 \mathrm{~dB}$ to identify the threshold at which an ABR waveform could be recognized and repeated. The ABR threshold was defined as the lowest stimulus at which recognizable ABR waves could be observed. If there were no detectable waveforms at $95 \mathrm{~dB}$ or greater, then the threshold was recorded as $95 \mathrm{~dB}$. The waveforms of ABR responses to click stimuli usually consist of 4 or 5 response peaks, labeled I, II, II, IV, and V.

Measurement of retinal ONL thickness. The animals were sacrificed and their eyes were enucleated with a hole made in the nasal ora serrata with a needle for orientation purposes. After fixation in $4 \%$ paraformaldehyde (in Dulbecco's phosphate-buffered saline [PBS]; Mediatech, Inc., Herndon, VA, USA) for 2 h, the cornea and lens of the eyes were removed. The remaining eyecups were immersed in the fixative solution for another $24 \mathrm{~h}$ at $4^{\circ} \mathrm{C}$. They were then rinsed with phosphate buffer, dehydrated in a graded ethanol series, and embedded in paraffin wax. Retinal sections of 4- $\mu$ m thickness were cut vertically through the optic nerve of each eye. The sections were stained with HE and evaluated by light microscopy. Images of the retinal sections were taken by a digital imaging system (DP71; Olympus, Tokyo, Japan). ONL thickness was analyzed by counting the rows of cell nuclei at a distance of $200 \mu \mathrm{m}$ from the optic nerve on both sides and then averaged.

Microscopic analysis of cochlear cross sections. Inner ears were dissected after the mice were euthanatized. A puncture hole was made in the apex of the cochlear to allow the fixative (4\% paraformaldehyde) to permeate fully. After fixing for $24 \mathrm{~h}$ at $4^{\circ} \mathrm{C}$, the inner ears were decalcified with $10 \%$ EDTA for 1 week at $4^{\circ} \mathrm{C}$. The specimens were embedded in paraffin after dehydration. Sections $(4 \mu \mathrm{m})$ were cut, mounted on glass slides, and counterstained in HE. Images were taken at $\times 400$ magnification using a digital imaging system (DP71; Olympus).

Electron microscopy scanning of the organ of Corti. After fixation and decalcification, the inner ears were dissected in PBS medium. The temporal bone, stria vascularis, Reissner's membrane, and tectorial membrane were removed to expose fully the hair cells in the organ of Corti. Tissues were stored in $4 \%$ glutaraldehyde overnight at $4^{\circ} \mathrm{C}$. Samples were washed in PBS and post-fixed in $1 \% \mathrm{OsO}_{4}$ for $30 \mathrm{~min}$. A graded series of ethanol were used to dehydrate the tissues, which were then critical point dried against liquid $\mathrm{CO}_{2}$ and sputter coated with platinum. Images of the outer and inner hair cells were taken by a field-emission scanning electron microscope (ULTRA 55; Zeiss, Oberkochen, Germany).

Exon trapping and sequence analysis. Genomic DNA was extracted from the tail tissue of mice.-Exon 


\section{Cellular Physiology Cell Physiol Biochem 2018;47:1883-1897 \begin{tabular}{l|l|l} 
DOI: 10.1159/000491068 & O 2018 The Author(s). Published by S. Karger AG, Basel \\
www.karger.com/cpb
\end{tabular} \\ Yan et al.: Natural Occurring Mouse Model with Adgrv1 Mutation}

sequencing of the targeted genes was then performed by Sangon Biotech Co., Ltd. (Shanghai, China). Briefly, DNA quality was assessed with $1 \%$ agarose gel electrophoresis and by the PicoGreen dsDNA Assay (Invitrogen, Carlsbad, CA, USA). All of the coding exons of the target genes were assessed for the detection of single nucleotide variants and insertion/deletions.

qRT-PCR. RNA was extracted from retinas using the TRIzol reagent (Invitrogen) and reverse transcribed into single-stranded cDNA using a Prime Script RT Kit (\#RR036A; Takara Biotechnology (Dalian) Co., Ltd., Dailian, China). The amplification and quantification of target genes were determined using a CFX Connect ${ }^{\mathrm{TM}}$ Real-Time PCR system (BIO-RAD, Hercules, CA, USA) with SYBR Premix (\#RR820A; TaKaRa). Amplification was performed for 40 cycles under the following conditions: $95^{\circ} \mathrm{C}$ for $45 \mathrm{~s}$, followed by 40 cycles at $58^{\circ} \mathrm{C}$ for $45 \mathrm{~s}$ and $72^{\circ} \mathrm{C}$ for $60 \mathrm{~s}$. The primers were synthesized by Sangon Biotech Co., Ltd. as follows:

Ush2a

5'-GTCACACATGCTTCCAGGTAATG-3' (forward)

5'-GGGAACGGTAAATGGCTCTCTA-3' (reverse)

Adgrv1

5'-TGACGACGATCTTCCGGAGC-3' (forward)

$5^{\prime}$-AGCCCTTGGCCATCCAAGTT-3' (reverse)

$\beta$-actin

5'-CTTCCTCCCTGGAGAAGAGCTATG-3' (forward)

5'-CCAAGAAGGAAGGCTGGAAAAGAG-3' (reverse)

All reactions were performed in triplicate. $\beta$-actin was used as an endogenous control. Gene expression levels were normalized to the expression levels of $\beta$-actin.

Whole exome sequencing. Genomic DNA was extracted from blood taken from the tail tissue. Whole exome sequencing was performed by Novogene Biotech Co., Ltd. (Beijing, China; Item No. \#P2016071069). Briefly, whole exome sequences were efficiently enriched from $1.0 \mu \mathrm{g}$ genomic DNA using a liquid capture system (SureSelectXT Mouse All Exon, Agilent Technologies, Inc., Santa Clara, CA, USA) according to the manufacturer's protocol. Firstly, qualified genomic DNA was randomly fragmented to an average size of 180-280 bp using a Covaris S220 sonicator. Secondly, the genomic DNA fragments were end repaired and phosphorylated, followed by A-tailing and ligation at the $3^{\prime}$ ends with paired-end adaptors (Illumina, San Diego, CA, USA) with a single "T" base overhang and purification using AMPure SPRI beads from Agencourt (Indianapolis, IN, USA). Then, the size distribution and concentration of the libraries were respectively determined by an Agilent 2100 Bioanalyzer and qualified using real-time PCR ( $2 \mathrm{nM}$ ). Finally, the DNA libraries were sequenced on an Illumina HiSeq 4000 for paired-end 150-bp reads.

Western blotting. Retinal tissue was collected and homogenized. After centrifugation, aliquot extracts containing equal amounts of protein $(30 \mu \mathrm{g})$ were electrophoresed, transferred to a membrane, and probed with primary antibodies against PDE6B (\#ab5663; Abcam, Cambridge, MA, USA; at a 1:1000 dilution) and GAPDH (\#10494-1-AP; Proteintech, Rosemont, IL, USA; at a 1:1000 dilution) at $4^{\circ} \mathrm{C}$ overnight. The membrane was incubated with a goat anti-rabbit horseradish peroxidase-conjugated secondary antibody (\#EK020; Zhuangzhi, Xi'an, China; at a 1:10000 dilution) at room temperature for $1 \mathrm{~h}$. The protein bands were detected by an enhanced chemiluminescence system (Thermo Fisher Scientific, Waltham, MA, USA). The intensity of the protein bands was determined using ImageJ software (National Institutes of Health, Bethesda, MD, USA). GAPDH was used as a loading control.

\section{Statistical analysis}

All data are expressed as the mean \pm standard error. Statistical differences among the animal groups were processed using analysis of variance followed by Bonferroni's post-hoc test in SPSS software (version 16.0, Chicago, IL, USA). The independent t-test was performed when only two groups were involved. A $P$-value $<0.05$ was considered statistically significant.

\section{Results}

Pedigree analysis of hybrids from crossing $K M^{\text {ush/ush }}$ mice with $\mathrm{CBA} / \mathrm{CaJ}$ mice

The F1 hybrids from crossing $\mathrm{KM}^{\text {ush/ush }}$ mice with $\mathrm{CBA} / \mathrm{CaJ}$ mice exhibited a normal ABR threshold (Fig. 1A) and normal ERG responses (Fig. 1B). The F2 offspring could be divided into four strains according to their phenotypes; namely, a strain with reduced ERG amplitudes (CBA-1 $\left.{ }^{\text {ush } / \text { ush }}\right)$, a strain with an elevated ABR threshold (CBA-2 ${ }^{\text {ush }} /$ ush $)$, a strain with 
Fig. 1. Auditory brainstem response (ABR) and electroretinogram (ERG) of $\mathrm{CBA} / \mathrm{CaJ}$ (F0-CBA) mice, and the F1 and F2 offspring from crossing $\mathrm{KM}^{\text {ush/ush }}$ mice with CBA/CaJ mice. A. Typical ABR waveforms and quantitative analysis of the thresholds of CBA/ $\mathrm{CaJ}$ and F1 mice at P21 ( $=6)$. ABR waveforms below $50 \mathrm{~dB}$ could be distinguished in the CBA/CaJ mice and F1 mice. The ABR threshold of the $\mathrm{CBA} / \mathrm{CaJ}$ mice was not significantly different from that of the F1 mice. Roman numerals $\mathrm{I}-\mathrm{V}$ indicate the 4 or 5 peaks in the ABR waveforms in response to click stimuli. N.S.: not significant. B. Typical ERG waveforms and quantitative analysis of the amplitudes in the CBA/CaJ and F1 mice at P21 $(n=6)$. The amplitude of the a-wave or b-wave in the CBA/CaJ mice was not significantly different from that of the F1 mice. N.S.: not significant. C. Typical ABR waveforms and quantitative analysis of the ABR thresholds in separated strains of the F2 offspring at P21 (n=6). ABR waveforms below $50 \mathrm{~dB}$ could be distinguished in the F2-CBA and F2-CBA-1 ${ }^{\text {ush/ }}$ ush mice, while the waveforms could be distinguished only above $80 \mathrm{~dB}$ in the F2-CBA-2 $2^{\text {ush/ush }}$ and F2-CBA- $3^{\text {ush/ush }}$ mice. The ABR threshold of the F2-CBA or F2-CBA-1 ${ }^{\text {ush/ush }}$ mice was significantly lower than that of the F2-CBA-2 ${ }^{\text {ush/ush }}$ and F2-CBA-3 ${ }^{\text {ush/ush }}$ mice. The ABR threshold of the F2-CBA mice was not significantly different from that of the F2-CBA-1 ${ }^{\text {ush/ush }}$ mice. The ABR threshold of the F2-CBA-2 ${ }^{\text {ush } / \text { ush }}$ mice was not significantly different from that of the F2-CBA- $3^{\text {ush } / \text { ush }}$ mice. \#\#P<0.01 vs. F2-CBA; ${ }^{* *} \mathrm{P}<0.01$ vs. F2-CBA- $1^{\text {ush/ush }}$. D. Typical ERG waveforms and quantitative analysis of the amplitudes in separated strains of the F2 offspring at P21 ( $=6)$. The ERG waveforms of the F2-CBA$1^{\text {ush/ush }}$ and F2-CBA- $3^{\text {ush/ush }}$ mice could not be distinguished from background physiological noise. The ERG waveforms of the F2-CBA and F2-CBA- $2^{\text {ush/ush }}$ mice were relatively normal. The a-wave or b-wave amplitude of the F2-CBA and F2-CBA- $2^{\text {ush/ush }}$ mice was significantly higher than that of the F2-CBA-1 ${ }^{\text {ush/ush }}$ and F2-CBA$3^{\text {ush/ush }}$ mice. The a-wave or b-wave amplitude of the F2-CBA mice was not significantly different from that of the F2-CBA-2 $2^{\text {ush/ush }}$ mice. The a-wave or b-wave amplitude of the F2-CBA- $1^{\text {ush/ush }}$ mice was not significantly different from that of the F2-CBA- $3^{\text {ush/ush }}$ mice. \#\#P<0.01 vs. F2-CBA- $1^{\text {ush } / \text { ush; }}{ }^{* *} \mathrm{P}<0.01$ vs. F2-CBA- $3^{\text {ush }}$ /ush.

both reduced ERG amplitudes and elevated ABR threshold (CBA-3 ${ }^{\text {ush/ush }}$ ), and a strain with normal ERG amplitudes and ABR threshold (CBA) (Fig. 1C, D).

After several generations, the propagation of $\mathrm{CBA}-1^{\text {ush/ush }}$ and CBA- $3^{\text {ush }} /$ ush mice was halted. We crossed male CBA/CaJ mice with the original F3 offspring of CBA-1 $1^{\text {ush } / \text { ush }}$ mice or the F4 offspring of CBA- $3^{\text {ush } / \text { ush }}$ mice to continue the inbreeding (Fig. 2, bold arrow). The segregation of the RP and hearing loss phenotypes appeared again after crossing CBA/CaJ mice with the F4 offspring of CBA- $3^{\text {ush } / \text { ush }}$ mice (Fig. 2, * and ${ }^{* *}$ ).

\section{Phenotypes and genotypes of CBA-1 ${ }^{\text {ush } / \text { ush }}$ mice}

The CBA-1 $1^{\text {ush/ush }}$ and $\mathrm{KM}^{\text {ush/ush }}$ mice showed an early onset of retinal degeneration with a waxy pallor appearance of the optic disc and attenuation of retinal vessels, as evidenced by fundus imaging and FFA examinations. OCT showed that the ONL of the CBA- $1^{\text {ush }}$ ush and $\mathrm{KM}^{\text {ush/ush }}$ mice almost disappeared at P21 (Fig. 3A). Retinal sections suggested there was only one layer of cell nuclei in the ONL of the CBA-1 $1^{\text {ush/ush }}$ and $\mathrm{KM}{ }^{\text {ush/ush }}$ mice (Fig. 3B). A significant 
Fig. 2. Pedigree of crossing $\mathrm{KM}^{\text {ush/ush }}$ mice with $\mathrm{CBA} / \mathrm{CaJ}$ mice. ERG+: mice without any distinguished ERG waveform; ABR+: mice with an elevated ABR threshold; Arrows: F3 offspring of CBA-1 ${ }^{\text {ush/ush }}$ mice or F4 offspring of CBA-3 $3^{\text {ush/ush }}$ mice were matched with $\mathrm{CBA} / \mathrm{CaJ}$ mice to continue inbreeding; *,**: offspring with the segregation of the RP and hearing loss phenotypes.

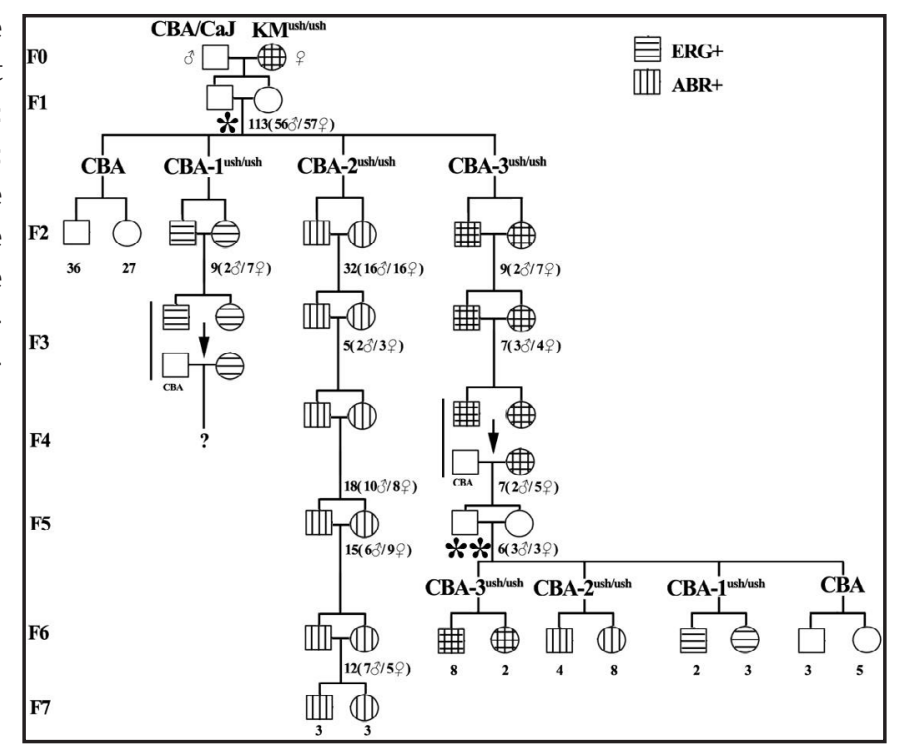

amount of PDE6B was detected in the KM and CBA/CaJ mice. Meanwhile, PDE6B was undetectable in the CBA-1 $1^{\text {ush }}$ ush and $\mathrm{KM}^{\text {ush/ush }}$ mice (Fig. 3C). DNA sequencing of Pde $6 b$ exons revealed five mutations in both the $\mathrm{CBA}-1^{\text {ush }} / \mathrm{ush}^{\text {and }} \mathrm{KM}{ }^{\text {ush }} /$ ush mice. These mutations occurred in exons 1, 4, 7, and 9, respectively. Four of the five mutations were silent and located within the coding region (data not shown). The only significant mutation (a $\mathrm{C}$ to $\mathrm{A}$ transversion at position 49 in exon 7) produced a nonsense mutation that converted codon 347, tyrosine (TAC), into a stop codon (TAA). This conversion would lead to premature chain termination during translation (Fig. 3D).

\section{Phenotypes and genotypes of CBA-2 $2^{\text {ush/ush }}$ mice}

Neither the a-wave nor b-wave amplitude in the ERG responses of the CBA-2 $2^{\text {ush/ush }}$ mice was significantly different from that of the CBA/CaJ mice at P14, P21, and P56 (all $P>0.05$ ) (Fig. 4A). No signs of retinal degeneration, such as a waxy pallor appearance of the optic disc and attenuation of retinal vessels, were found in the CBA- $2^{\text {ush/ush }}$ mice at P21 under fundus imaging and FFA (Fig. 4B). with no significant differences in ONL thickness measured on the retinal sections compared with that of the CBA/CaJ mice at P14, P21, and P56 (all $P>0.05$ ) (Fig. 4C).

The CBA-2 ${ }^{\text {ush/ush }}$ mice showed no obvious waveform in response to 90-dB SPL at P14. Meanwhile, the ABR threshold of the CBA/CaJ mice was approximately 40-dB SPL. At P21 and P56, the phenotype of hearing loss in the CBA-2 ${ }^{\text {ush/ush }}$ mice was similar to that at P14 (Fig. 5A). The degeneration of the organ of Corti and spiral ganglion cells was remarkable, as shown in cross sections of the basal turn of the cochlear in the CBA-2 ${ }^{\text {ush }} /$ ush $m i c e$ at P56 (Fig. 5B). Electron microscopy scanning of the organ of Corti suggested that a large proportion of stereocilia bundles in the outer hair cells of the CBA-2 ${ }^{\text {ush } / \text { ush }}$ mice had vanished (Fig. 5C-a). The remaining bundles of the outer hair cells lost their polarity and graded height. These stereocilia bundles were deformed and failed to form the characteristic V-shaped structure (Fig. 5C-b). However, these pathologies could not be found in the outer hair cells of agematched $\mathrm{CBA} / \mathrm{CaJ}$ mice. The structure of stereocilia bundles in the inner hair cells of the CBA-2 ${ }^{\text {ush } / \text { ush }}$ mice showed no significant difference compared with the CBA/CaJ mice (Fig. $5 \mathrm{C}-\mathrm{c})$.

Whole exome sequencing identified a base pair deletion at nt6748 of Adgrv1 in the F3 and F6 offspring of CBA-2 ${ }^{\text {ush } / \text { ush }}$ mice. The $\mathrm{KM}^{\text {ush/ush }}$ mice also showed a similar base pair deletion. This mutation would cause a frameshift and a premature stop codon (TAA) following amino acid 2250. Exon sequencing of the F2 hybrids with hearing loss also showed a similar 
Fig. 3. Ocular phenotypes and genotypes of $\mathrm{CBA}-1^{\text {ush/ush }}$ mice. A. Typical fundus, FFA, and OCT images from CBA/ $\mathrm{CaJ}, \mathrm{CBA}-1^{\text {ush }} /$ ush, $\mathrm{KM}$, and $\mathrm{KM}^{\text {ush/ush }}$ mice at P21 $(n=6)$. There were signs of retinal degeneration in the CBA- $1^{\text {ush/ush }}$ and $\mathrm{KM}^{\text {ush/ush }}$ mice, such as a waxy pallor appearance of the optic disc, attenuation of retinal vessels, and reduced thickness of the ONLs. B. Retinal sections with He staining from CBA/CaJ, CBA- $1^{\text {ush } / \text { ush }}$, KM and $\mathrm{KM}^{\text {ush/ush }}$ mice at P21 ( $\left.\mathrm{n}=6\right)$. Compared to the CBA/CaJ and KM mice, only one layer of the ONL remained in the retinas of CBA-1 $1^{\text {ush/ush }}$ and $\mathrm{KM}^{\text {ush/ush }}$ mice. ONL: outer nuclear layer; INL: inner nuclear layer; GCL: ganglion cell layer. C. Representative western blotting bands of PDE6B in retinas from CBA/CaJ, CBA$1^{\text {ush }}$ ush, $\mathrm{KM}$, and $\mathrm{KM}^{\text {ush }}$ ush mice at P21 (n = 3). The PDE6B protein level was substantially higher in the CBA/CaJ and KM mice than in the CBA- $1^{\text {ush/ush }}$ and $\mathrm{KM}^{\text {ush/ }}$ ${ }^{\text {ush }}$ mice. D. Exon sequencing of Pde6b in the $\mathrm{CBA} / \mathrm{CaJ}, \mathrm{CBA}-1^{\text {ush/ush }}, \mathrm{KM}$, and $\mathrm{KM}^{\text {ush/ }}$ ${ }^{\text {ush }}$ mice at P21 ( $\left.\mathrm{n}=3\right)$. A $\mathrm{C}$ to A transversion at position 49 in exon 7 was found in the CBA-1 $1^{\text {ush/ush }}$ and $\mathrm{KM}^{\text {ush/ush }}$ mice. This mutation produced a nonsense mutation that converted codon 347, tyrosine (TAC), into a stop codon (TAA). WT: exon sequence from the National Center for Biotechnology Information; arrows: the mutation.

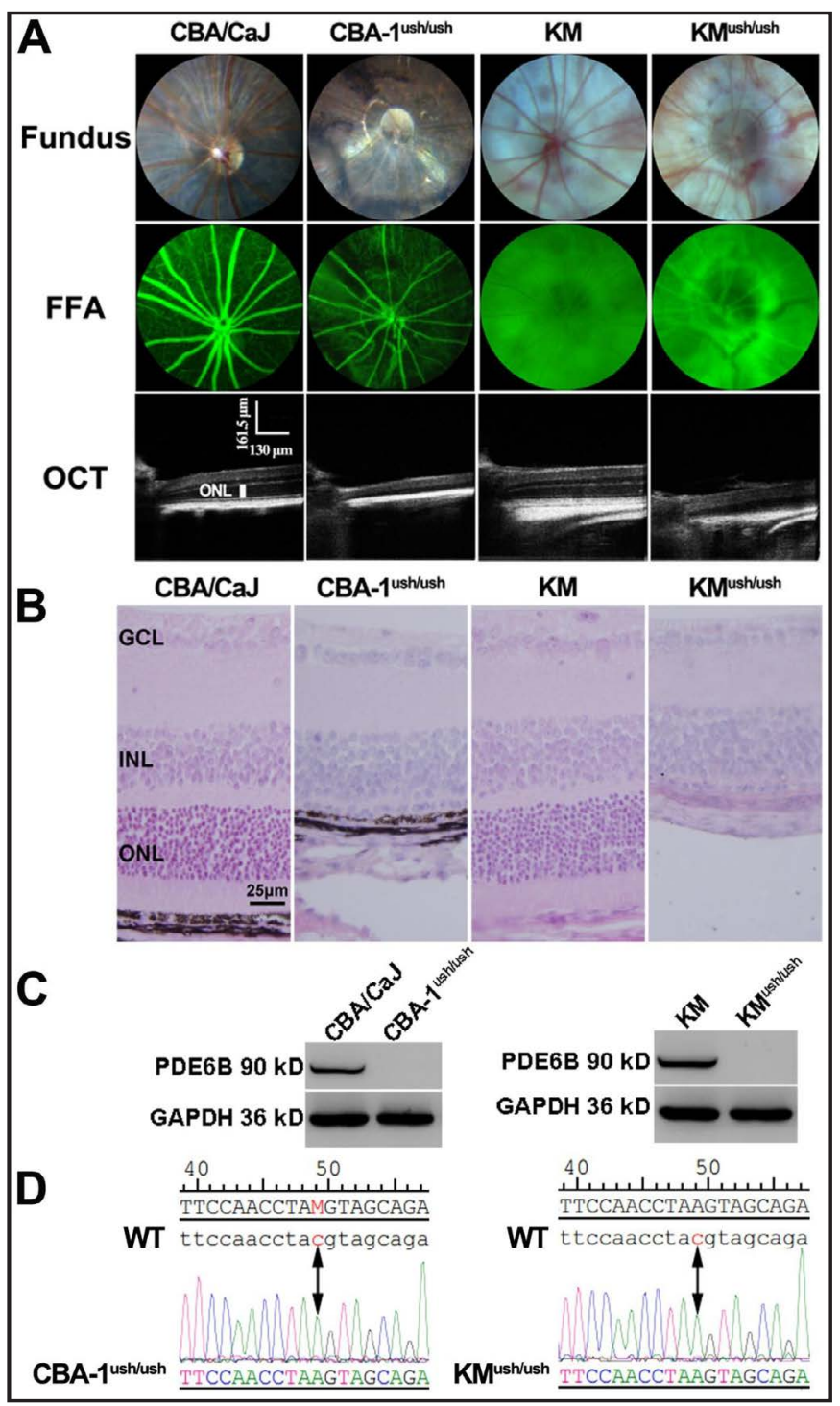

deletion mutation of Adgrv1 (Fig. 5D). On the other hand, the offspring with normal hearing ability did not carry the deletion mutation. qRT-PCR analysis suggested that the mRNA level of Ush $2 a$ in the retina of the CBA-2 ${ }^{\text {ush/ush }}$ mice was not significantly different from that in the $\mathrm{CBA} / \mathrm{CaJ}$ mice $(P>0.05)$, while its level was dramatically reduced in the $\mathrm{KM}^{\text {ush }} / \mathrm{ush}$ and rd1 mice $(P<0.0001)$ (Fig. 5E-a). The decreased level of Ush2a mRNA in the KM ${ }^{\text {ush }} /$ ush $m i c e$ agreed well with a previous report [15]. The level of Adgrv1 mRNA was significantly lower in the CBA-2 $2^{\text {ush/ush }}$ mice than in the CBA/CaJ mice $(P<0.01)$ (Fig. 5E-b). However, the level of Adgrv1 mRNA in the $\mathrm{KM}^{\text {ush } / \text { ush }}$ and $\mathrm{rd} 1$ mice was also dramatically decreased compared to the CBA/CaJ mice $(P<0.0001)$ (Fig. 5E-b).

\section{Phenotypes and genotypes of CBA-3 $3^{\text {ush/ush }}$ mice}

Fundus imaging and FFA suggested that there was severe retinal degeneration with the attenFundus imaging and FFA suggested that there was severe retinal degeneration with the attenuation of retinal vessels in the CBA- $3^{\text {ush } / \text { ush }}$ mice (Fig. 6A). The ONL in the retina of the CBA- $3^{\text {ush/ush }}$ mice was almost lost, as shown in the OCT images and retinal sections (Fig. $6 \mathrm{~A}, \mathrm{~B})$. Western blotting suggested that retinal PDE6B had vanished in the CBA-3 ${ }^{\text {ush } / \text { ush }}$ mice, which should be attributed to the nonsense mutation in exon 7 of Pde6b (Fig. 6C, D). 
Fig. 4. Ocular phenotypes of $\mathrm{CBA}-2^{\text {ush/ush }}$ mice. A. Typical ERG waveforms and quantitative analysis of a-wave or b-wave amplitude in the CBA-2 $2^{\text {ush }}$ ush and CBA/CaJ mice at P14, P21, and P56 (n=6). The a-wave or b-wave amplitude of the CBA-2 ${ }^{\text {ush/ush }}$ mice was not significantly different from that of the CBA/CaJ mice at each time point. N.S.: not significant. B. Typical FFA and OCT images of the CBA-2 $2^{\text {ush/ush }}$ and CBA/CaJ mice at P21 ( $\mathrm{n}=3)$. No signs of retinal degeneration were found in the CBA-2 $2^{\text {ush/ush }}$ mice. C. Retinal sections with HE staining and quantitative analysis of ONL thickness in the CBA-2 $2^{\text {ush/ush }}$ and CBA/CaJ mice at P14, P21, and P56 $(n=6)$. ONL thickness was not significantly different between the CBA-2 ${ }^{\text {ush/ush }}$ mice and $\mathrm{CBA} / \mathrm{CaJ}$ mice at each time point. N.S.: not significant.

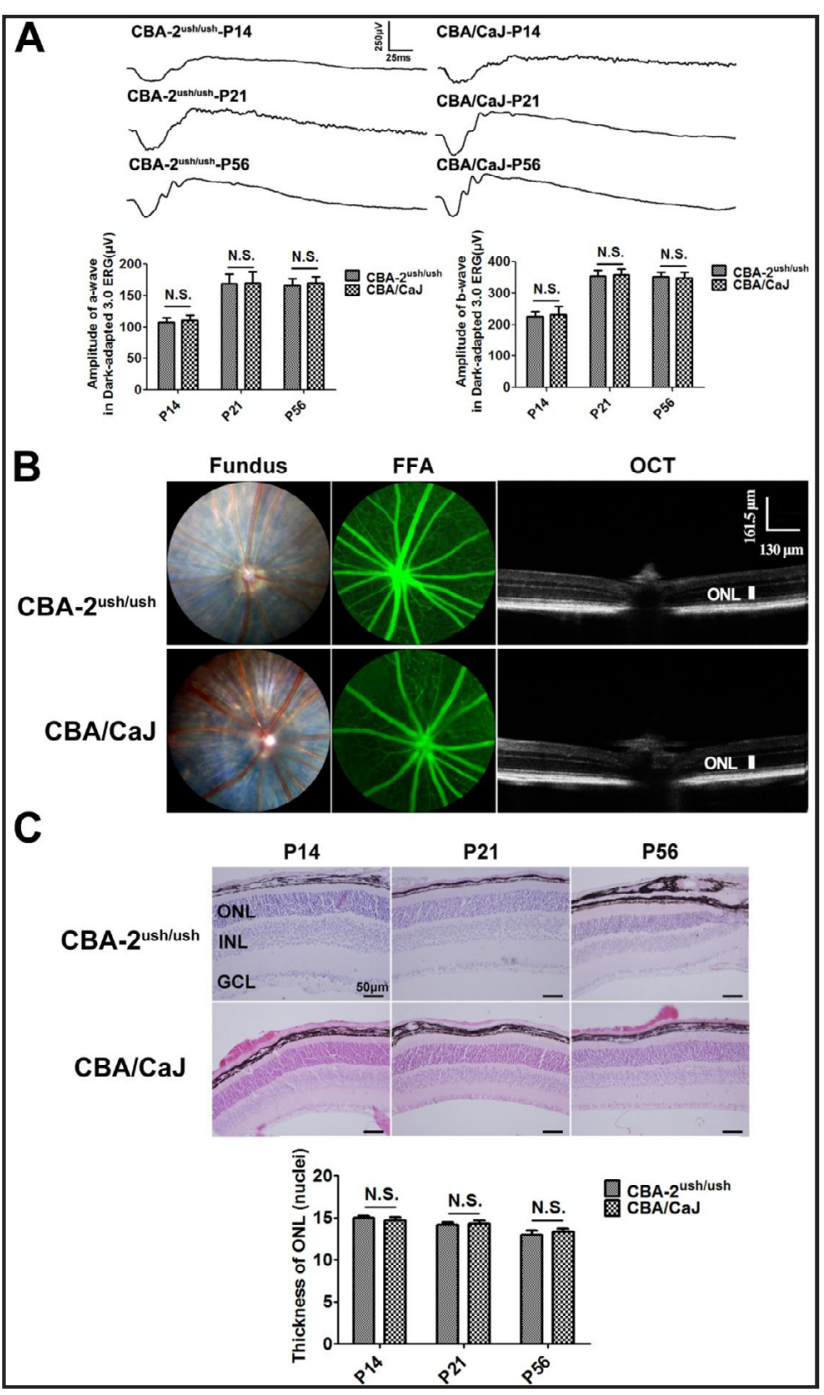

Degeneration of the organ of Corti and spiral ganglion cells was pronounced in the basal turn of the cochlear in the CBA- $3^{\text {ush/ush }}$ mice at P56, as evidenced by the cross sections of the cochlear (Fig. 6E). The stereocilia bundles of the outer hair cells degenerated in the CBA-3 ${ }^{\text {ush } /}$ ush mice, with the remaining outer hair cells appearing deformed, as shown in the electron microscopy scanning images (Fig. 6F). Exon sequence analysis of Adgrv1 found a base pair deletion at nt6748 in the CBA-3 $3^{\text {ush/ush }}$ mice. This deletion would cause a frameshift and a premature stop codon following amino acid 2250 (Fig. 6G).

\section{Discussion}

Human USH is closely associated with spontaneous mutations in multiple genes [29]. Hitherto, the majority of USH mouse models have been generated by transgenic technology or induced by ethylnitrosourea [30,31]. However, these models may not mimic reliably the clinical traits of human USH. On the basis of our previous findings [15], the present study established a spontaneous mutant USH mouse model by crossing hearing-impaired $\mathrm{KM}^{\text {ush } /}$ ush mice with CBA/CaJ mice. ERG reflects retinal function [32], while ABR reflects hearing ability [33]. According to the normal ABR and ERG responses of the F1 hybrids, and the segregation of the RP and hearing loss phenotypes in the F2 offspring, we could deduce that 
Fig. 5. Auditory phenotypes and genotypes of CBA-2 $2^{\text {ush/ush }}$ mice. A. Typical ABR waveform and quantitative analysis of ABR threshold in the CBA$2^{\text {ush/ush }}$ and $\mathrm{CBA} / \mathrm{CaJ}$ mice at P14, P21, and P56 ( $=$ 6). The ABR threshold of the CBA-2 $2^{\text {ush/ush }}$ mice was significantly higher than that of the CBA/CaJ mice at each time point. Roman numeral $\mathrm{I}-\mathrm{V}$ indicate the 4 or 5 peaks in the ABR waveforms in response to click stimuli. ${ }^{* *} \mathrm{P}<0.01$. B. Typical cochlear sections with HE staining of the CBA-2 $2^{\text {ush/ush }}$ mice at P56 ( $n=3)$. Degeneration of the organ of Corti and spiral ganglion cells was

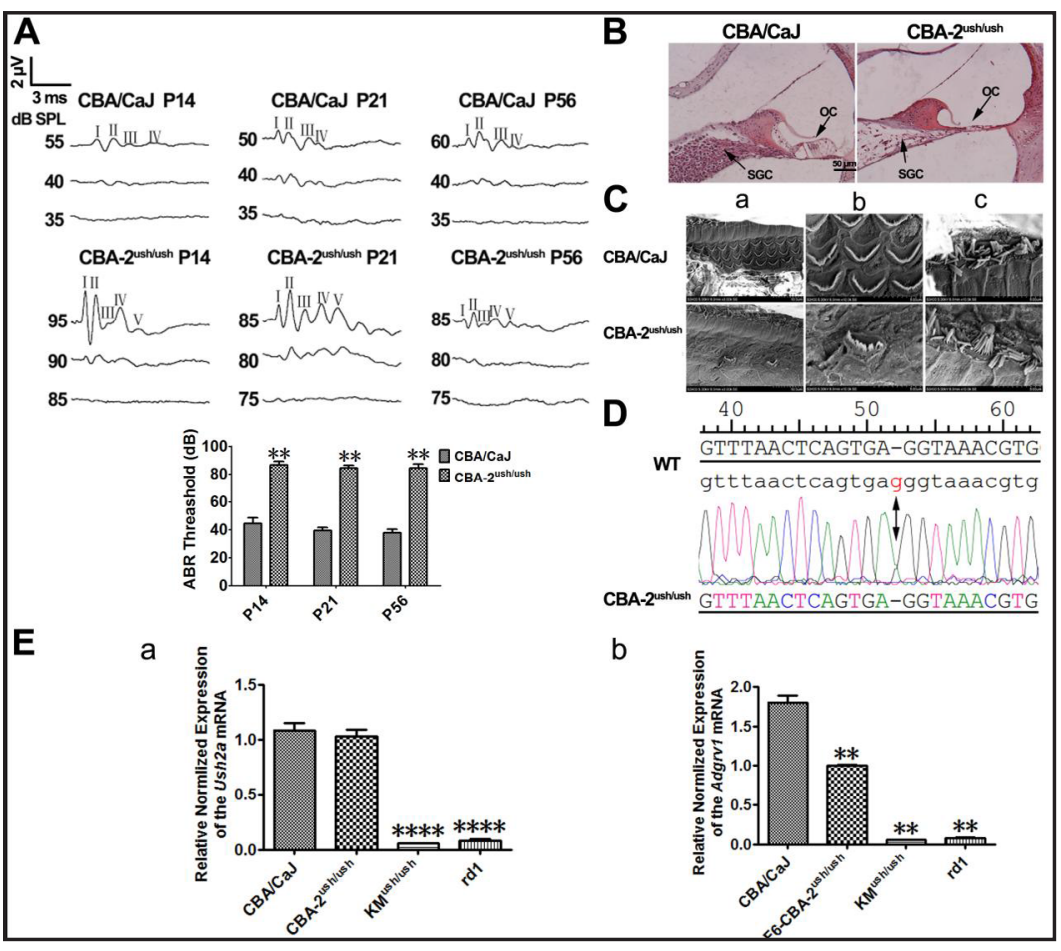
pronounced in the basal turn of the cochlear in the CBA-2 ${ }^{\text {ush/ush }}$ mice. OC: organ of Corti; SGC: spiral ganglion cells. C. Ultrastructural changes of the cochlea by scanning electron microscopy in the CBA-2 $2^{\text {ush }}$ ush mice at P56 ( $\mathrm{n}=3$ ); (a) overall view of the organ of Corti at $\times 3000$ magnification; (b) outer hair cells at $\times 10000$ magnification; (c) inner hair cells at $\times 10000$ magnification. A large number of the stereocilia bundles in the outer hair cells of the CBA$2^{\text {ush/ush }}$ mice were missing, while the inner hair cells remained unchanged. D. Exon sequencing of Adgrv1 in the CBA-2 ${ }^{\text {ush } / \text { ush }}$ mice at P21 $(n=3)$. There was a base pair deletion at nt6748 of Adgrv1 in the CBA-2 ${ }^{\text {ush/ush }}$ mice, which would cause a frameshift and a premature-stop codon (TAA) following amino acid 2250. WT: exon sequence from the National Center for Biotechnology Information; arrows: the mutation. E. The retinal levels of Ush2a (a) and Adgrv1 (b) mRNA in the CBA/CaJ, CBA- $2^{\text {ush/ush }}, \mathrm{KM}^{\text {ush }}$ /ush, and rd1 mice at P21 ( $\mathrm{n}=3$ ). The retinal level of Ush2a mRNA in the CBA-2 ${ }^{\text {ush/ush }}$ mice was not significantly different from that in the CBA/ $\mathrm{CaJ}$ mice, while its level in the $\mathrm{KM}^{\text {ush/ush }}$ and $\mathrm{rd} 1$ mice was dramatically reduced. The retinal level of Adgrv1 mRNA was significantly lower in the CBA- $2^{\text {ush/ush }}$ mice than in the CBA/CaJ mice. Adgrv1 mRNA level in the $\mathrm{KM}^{\text {ush/ush }}$ and $\mathrm{rd} 1$ mice was significantly decreased from that in the $\mathrm{CBA} / \mathrm{CaJ}$ mice. ${ }^{* *} \mathrm{P}<0.01$ vs. CBA/CaJ mice; $^{* * * *} \mathrm{P}<0.0001$ vs. CBA/CaJ mice.

the F1 hybrids were heterozygotes and the mutated genes were inherited in an autosomal recessive mode.

$P d e 6 b$ encodes the rod cGMP-specific $3^{\prime}, 5^{\prime}$ cyclic phosphodiesterase subunit of the protein complex PDE6 [34]. This protein is essential for normal PDE6 functioning and plays a crucial role in visual signal transmission. A nonsense mutation in Pde6b would induce a calcium burst in photoreceptors due to the continuous opening of the calcium ion channel [35]. This mutation would result in photoreceptor apoptosis in humans [36,37] and mice $[18,38]$. In the present study, the mutated Pde6b might act as the underlying cause for the $\mathrm{RP}$ phenotype in the CBA-1 $1^{\text {ush/ush }}$ and $\mathrm{CBA}-3^{\text {ush/ush }}$ mice, as there was an original nonsense mutation in the $\mathrm{KM}^{\text {ush/ush }}$ mice. Subsequently, this hypothesis was confirmed by exon sequencing and western blotting of PDE6B. The relationship between a nonsense mutation of Pde6b and the RP phenotype has also been verified in other rd1 mouse models with different backgrounds[27].

Ush2 $a$ encodes the Usherin protein, which is vital for the development and homeostasis of the inner ear and retina. Mutations within this gene are closely associated with USH2A 
Fig. 6. Phenotypes and genotypes of the CBA$3^{\text {ush } / \text { ush }}$ mice. A. Fundus, FFA, and OCT images of the CBA- $3^{\text {ush/ush }}$ and $\mathrm{CBA} / \mathrm{CaJ}$ mice at P21 ( $\mathrm{n}=3)$. There were signs of retinal degeneration in the CBA-3 $3^{\text {ush }}$ ush mice, such as a waxy pallor appearance of the optic disc, attenuation of retinal vessels, and loss of the outer nuclear layers (ONLs). B. Retinal sections with $\mathrm{HE}$ staining of the CBA-3 $3^{\text {ush/ush }}$

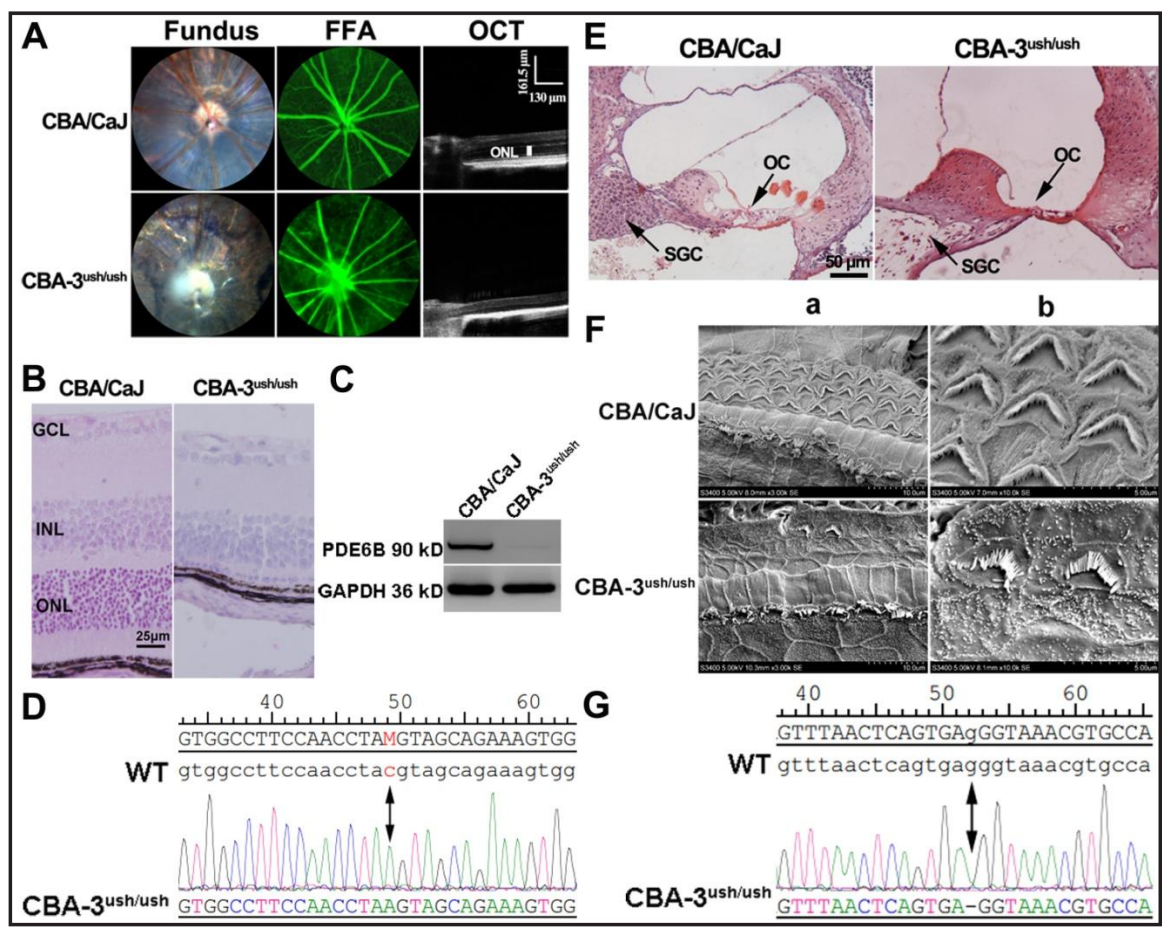
mice at P21 $(n=6)$. Only one layer of the ONL was left in the retina of the CBA-3 $3^{\text {ush }}$ ush mice at P21. C. Representative western blotting bands of PDE6B in the retinas from the CBA- $3^{\text {ush }} /$ ush and CBA/CaJ mice at P21 (n = 3). Western blotting suggested that the level of PDE6B was significantly lower in the CBA-3 ${ }^{\text {ush } / \text { ush }}$ mice than in the CBA/CaJ mice. D. Exon sequencing of Pde6b in the CBA-3 ${ }^{\text {ush/ush }}$ mice. A C to A transversion at position 49 in exon 7 was found in the CBA- $3^{\text {ush/ush }}$ mice. This mutation produced a nonsense mutation that converted codon 347, tyrosine (TAC), into a stop codon (TAA). WT: exon sequence from the National Center for Biotechnology Information; arrows: the mutation. E: Cochlear section (HE staining) of the CBA-3 ${ }^{\text {ush/ush }}$ and CBA mice at P56 $(n=3)$. The organ of Corti and spiral ganglion cells had degenerated in the CBA-3 ${ }^{\text {ush/ush }}$ mice. F. Ultrastructural changes of the cochlea by scanning electron microscopy in the CBA-3 ${ }^{\text {ush/ush }}$ mice at P56 ( $n=$ $3)$; (a) overall view of the organ of Corti at $\times 3000$ magnification; (b) outer hair cells at $\times 10000$ magnification. A large number of the stereocilia bundles in the outer hair cells from the CBA-3 ${ }^{\text {ush/ush }}$ mice had been lost, while the inner hair cells remained unchanged. G. Exon sequencing of Adgrv1 in the CBA-3 ${ }^{\text {ush } / \text { ush }}$ mice at P21 $(n=3)$. There was a base pair deletion at nt6748 of Adgrv1 in the CBA-3 ${ }^{\text {ush/ush }}$ mice. This mutation would cause a frameshift and a premature stop codon (TAA) following amino acid 2250. WT: exon sequence from the National Center for Biotechnology Information; arrows: the mutation.

$[39,40]$. We found that the Ush $2 a$ gene of the KM ${ }^{\text {ush/ush }}$ mice had 17 missense mutations (data not shown). Moreover, the level of Ush2a mRNA in the $\mathrm{KM}^{\text {ush/ush }}$ mice was much lower than that in the KM mice. Thus, the mutated Ush2a was previously deemed to act as the underlying cause for the hearing loss in KM ${ }^{\text {ush/ush }}$ mice [15]. However, after crossing KM ${ }^{\text {ush/ush }}$ mice with CBA/CaJ mice, the level of Ush2a mRNA was not significantly different between the CBA-2 $2^{\text {ush/ }}$ ush mice and CBA/CaJ mice. Meanwhile, the hearing loss phenotype was retained in the CBA$2^{\text {ush/ush }}$ mice.

A nonsense mutation of a gene always induces a specific reduction in the corresponding mRNA in many diseases $[18,41]$. On the other hand, a missense mutation usually does not interfere with mRNA synthesis. As usherin is mainly located in the periciliary membrane complex of photoreceptors [12], the loss of photoreceptors during retinal degeneration might contributed to the reduced level of Ush 2 a mRNA in the KM ${ }^{\text {ush/ush }}$ mice. This hypothesis was subsequently demonstrated by the decreased level of Ush $2 a$ mRNA in the retina of rd1 mice. Rd1 mice have normal hearing ability, while their photoreceptors are almost completely lost at P21 [42]. Thus, the reduced level of Ush2a mRNA in the retina of $\mathrm{rd} 1$ mice was actually 
due to photoreceptor loss, and not the decreased transcription of Ush2a. Besides, a nonsense mutation of a gene would lead to the premature termination of its protein translation and would probably change the associated phenotype [43]. It has been shown a nonsense mutation of $P d e 6 b$ contributes critically to the RP phenotype. In this context, we assumed that a nonsense mutation in another unknown gene acts as the original cause for the hearing loss in the $\mathrm{KM}^{\text {ush/ush }}$ and CBA-2 ${ }^{\text {ush/ush }}$ mice. Accordingly, whole exome sequencing found a common base deletion in Adgrv1. This deletion produced a nonsense mutation in the following DNA sequence of Adgrv1 in the CBA-2 ${ }^{\text {ush/ush }}$ and $\mathrm{KM}^{\text {ush } / \text { ush }}$ mice.

Adgrv1, which is also known as Gpr98, comprises 90 exons. ADGRV1 is expressed predominately in the embryonic central nervous system and eye of mice $[44,45]$. Clinical studies have suggested that homologous human gene (MASS1 or VLGR1) mutations are implicated in the pathogenesis of USH2C [46-48]. Furthermore, mice carrying a targeted mutation in Adgrv1 also suffer from degeneration of stereocilia bundles in the outer hair cells and hearing loss[45]. The spontaneous 7009G deletion in exon 27 of Adgrv1 is responsible for the hearing impairment of BUB/BnJ mice, which is suggested as an USH2C model [49]. In view of the close relationship between Adgrv1 mutation and hearing impairment in USH2C mice, it is highly possible that the hearing loss in the CBA-2 $2^{\text {ush/ush }}$ and $\mathrm{KM}^{\text {ush/ush }}$ mice might also be caused by the identified nonsense mutation in Adgrv1. This hypothesis is verified by the fact that CBA-2 ${ }^{\text {ush } / \text { ush }}$ mice with hearing loss retained the mutated Adgrv1. In contrast, the recombinant offspring without the Adgrv1 mutation had normal hearing ability and cochlear structure.

The USH1B mouse model with mutations in Myo7a [50], the USH2A mouse model with a targeted mutation in Ush2a [40], and another USH2C mouse model carrying a targeted mutation in Vlgr1 [45] exhibit abnormal visual function, similar to USH2 patients. In our study, the impact of the mutated Adgrv1 on visual function could not be evaluated on the $\mathrm{KM}^{\text {ush/ush }}$ or CBA-3 ${ }^{\text {ush/ush }}$ mice, as these mice are homozygous for the RP mutation. Our results confirmed that the CBA-2 ${ }^{\text {ush/ush }}$ mice did not exhibit the RP phenotype, even at P56. A previous study suggested that the photoreceptor degeneration in Ush2a knockout mice progresses slowly and becomes obvious at the age of 20 months [40]. Additionally, visual impairments in USH patients only become apparent in the second decade of life [48]. Likewise, the CBA-2 ${ }^{\text {ush }}$ ush mice may not live long enough to manifest profound signs of RP. Furthermore, the same gene mutation may lead to different phenotypes when animal models with different backgrounds are crossed. For example, the $\mathrm{crb} 1^{\text {rd } 8}$ mutation in $\mathrm{C} 3 \mathrm{H} / \mathrm{HeJ}$ mice exhibits a positive phenotype, while the same mutation in C57BL/6J mice causes no abnormal phenotype [51]. Thus, the absence of the RP phenotype in the CBA- $2^{\text {ush/ush }}$ mice might also be caused by their different background from other USH models [45].

The co-occurrence of Pde6b and Adgrv1 mutations has been reported in an USH human family [52]. In this case, some offspring of the family with both mutated genes exhibit a more severe ocular phenotype than the other members with only a mutation of Adgrv1. The co-mutation of Pde6b and Adgrv1 in the CBA-3 ${ }^{\text {ush/ush }}$ mice, which have more severe retinal degeneration than the CBA-2 $2^{\text {ush/ush }}$ mice, could well mimic such a situation. The retinal degeneration caused by USH genes is usually milder and occurs later than that caused by Pde6b. In the present study, the degree of the RP phenotype in the CBA- $3^{\text {ush/ush }}$ mice was similar to that in the CBA- $1^{\text {ush/ush }}$ mice. Additionally, the hearing loss phenotype was similar between the CBA-3 ${ }^{\text {ush/ush }}$ and CBA-2 $2^{\text {ush/ush }}$ mice. We speculate that there is not any mutual promotion effect between Pde6b and Adgrv1.

In conclusion, this study verified the underlying reason for the hearing loss in $\mathrm{KM}^{\text {ush }} /$ ush and CBA-2 ${ }^{\text {ush/ush }}$ mice. Moreover, we characterized the phenotypes and genotypes of recombinant inbred strains from intercrossing $\mathrm{KM}^{\text {ush/ush }}$ mice with CBA/CaJ mice. Our results suggest that CBA-2 $2^{\text {ush/ush }}$ mice could be used as an animal model with an spontaneously inherited phenotype of hearing loss and mutation in Adgrv1, the human Usher syndrome 2C gene. To our knowledge, this work is the first time that a mouse strain with hearing loss has been isolated from RP ancestors, which would be beneficial for studying the pathological mechanism underlying RP/USH and developing therapeutic strategies. Further study is 


\section{Cellular Physiology Cell Physiol Biochem 2018;47:1883-1897

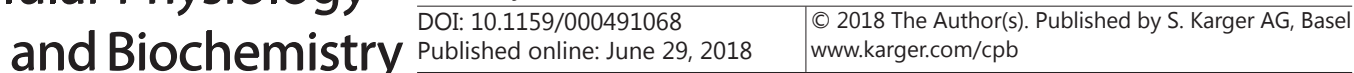 \\ Yan et al.: Natural Occurring Mouse Model with Adgrv1 Mutation}

needed for continuous observation of the ocular phenotype in the CBA-2 ${ }^{\text {ush/ush }}$ mice to verify the impact of the mutant Adgrv1 gene on retinal function and structure.

\section{Acknowledgements}

This work was supported by grants from the Army Laboratory Animal Foundation of China (SYDW [2014]008), the Foundation of Open Sharing Platform of Science and Technology of Shaanxi Province, China (2015FWPT-02), Shaanxi Province and Ministry of Education Natural Science Foundation (17JK0216) and the Beijing Natural Science Foundation (No. 7162180).

\section{Disclosure Statement}

The authors declare that no conflict of interests exists.

\section{References}

1 Sullivan LS, Bowne SJ, Koboldt DC, Cadena EL, Heckenlively JR, Branham KE, Wheaton DH, Jones KD, Ruiz RS, Pennesi ME, Yang P, Davis-Boozer D, Northrup H, Gurevich VV, Chen R, Xu M, Li Y, Birch DG, Daiger SP: A novel dominant mutation in SAG, the arrestin-1 gene, is a common cause of retinitis pigmentosa in hispanic families in the southwestern United States. Invest Ophthalmol Vis Sci 2017;58:2774-2784.

- Haer-Wigman L, Newman H, Leibu R, Bax NM, Baris HN, Rizel L, Banin E, Massarweh A, Roosing S, Lefeber DJ, Zonneveld-Vrieling MN, Isakov O, Shomron N, Sharon D, Den Hollander AI, Hoyng CB, Cremers FP, BenYosef T: Non-syndromic retinitis pigmentosa due to mutations in the mucopolysaccharidosis type IIIC gene, heparan-alpha-glucosaminide N-acetyltransferase (HGSNAT). Hum Mol Genet 2015;24:3742-3751.

-3 McGee TL, Seyedahmadi BJ, Sweeney MO, Dryja TP, Berson EL: Novel mutations in the long isoform of the USH2A gene in patients with Usher syndrome type II or non-syndromic retinitis pigmentosa. J Med Genet 2010;47:499-506.

4 Kletke S, Batmanabane V, Dai T, Vincent A, Li S, Gordon KA, Papsin BC, Cushing SL, Heon E: The combination of vestibular impairment and congenital sensorineural hearing loss predisposes patients to ocular anomalies, including Usher syndrome. Clin Genet 2017;92:26-33.

5 Zou J, Mathur PD, Zheng T, Wang Y, Almishaal A, Park AH, Yang J: Individual USH2 proteins make distinct contributions to the ankle link complex during development of the mouse cochlear stereociliary bundle. Hum Mol Genet 2015;24:6944-6957.

6 Koparir A, Karatas OF, Atayoglu AT, Yuksel B, Sagiroglu MS, Seven M, Ulucan H, Yuksel A, Ozen M: Wholeexome sequencing revealed two novel mutations in Usher syndrome. Gene 2015;563:215-218.

7 Petit C: Usher syndrome: from genetics to pathogenesis. Annu Rev Genomics Hum Genet 2001;2:271-297.

-8 Mustapha M, Chouery E, Torchard-Pagnez D, Nouaille S, Khrais A, Sayegh FN, Megarbane A, Loiselet J, Lathrop M, Petit C, Weil D: A novel locus for Usher syndrome type I, USH1G, maps to chromosome 17q2425 Hum Genet 2002;110:348-350.

-9 Pieke-Dahl S, Moller CG, Kelley PM, Astuto LM, Cremers CW, Gorin MB, Kimberling WJ: Genetic heterogeneity of Usher syndrome type II: localisation to chromosome 5q. J Med Genet 2000;37:256-262.

10 Joensuu T, Hamalainen R, Yuan B, Johnson C, Tegelberg S, Gasparini P, Zelante L, Pirvola U, Pakarinen L, Lehesjoki AE, de la Chapelle A, Sankila EM: Mutations in a novel gene with transmembrane domains underlie Usher syndrome type 3 Am J Hum Genet 2001;69:673-684.

11 Alagramam KN, Yuan H, Kuehn MH, Murcia CL, Wayne S, Srisailpathy CR, Lowry RB, Knaus R, Van Laer L, Bernier FP, Schwartz S, Lee C, Morton CC, Mullins RF, Ramesh A, Van Camp G, Hageman GS, Woychik RP, Smith RJ: Mutations in the novel protocadherin PCDH15 cause Usher syndrome type 1F. Hum Mol Genet 2001;10:1709-1718.

12 Zou J, Luo L, Shen Z, Chiodo VA, Ambati BK, Hauswirth WW, Yang J: Whirlin replacement restores the formation of the USH2 protein complex in whirlin knockout photoreceptors. Invest Ophthalmol Vis Sci 2011;52:2343-2351. 


\section{Cellular Physiology Cell Physiol Biochem 2018;47:1883-1897 \begin{tabular}{l|l|l}
\hline DOI: 10.1159/000491068 & $\begin{array}{l}\text { C } 2018 \text { The Author(s). Published by S. Karger AG, Basel } \\
\text { www.karger.com/cpb }\end{array}$ \\
\hline
\end{tabular}}

13 Http://www.informatics.jax.org/disease/DOID:0050439?openTab=models

14 Http://www.informatics.jax.org/disease/DOID:0110839?openTab=models

15 Yao L, Zhang L, Qi LS, Liu W, An J, Wang B, Xue JH, Zhang ZM: The time course of deafness and retinal degeneration in a Kunming mouse model for Usher syndrome. PLoS One 2016;11:e155619.

-16 Davis RJ, Tosi J, Janisch KM, Kasanuki JM, Wang NK, Kong J, Tsui I, Cilluffo M, Woodruff ML, Fain GL, Lin CS, Tsang SH: Functional rescue of degenerating photoreceptors in mice homozygous for a hypomorphic cGMP phosphodiesterase 6 b allele (Pde6bH620Q). Invest Ophthalmol Vis Sci 2008;49:5067-5076.

17 Shu HR, Bi H, Pan YC, Xu HY, Song JX, Hu J: Targeted exome sequencing reveals novel USH2A mutations in Chinese patients with simplex Usher syndrome. Bmc Med Genet 2015;16:83.

-18 Pittler SJ, Baehr W: Identification of a nonsense mutation in the rod photoreceptor cGMP phosphodiesterase beta-subunit gene of the rd mouse. Proc Natl Acad Sci U S A 1991;88:8322-8326.

19 Dreyer B, Brox V, Tranebjaerg L, Rosenberg T, Sadeghi AM, Moller C, Nilssen O: Spectrum of USH2A mutations in Scandinavian patients with Usher syndrome type II. Hum Mutat 2008;29:451.

20 Xu W, Dai H, Lu T, Zhang X, Dong B, Li Y: Seven novel mutations in the long isoform of the USH2A gene in Chinese families with nonsyndromic retinitis pigmentosa and Usher syndrome Type II. Mol Vis 2011;17:1537-1552.

21 Rivolta C, Sweklo EA, Berson EL, Dryja TP: Missense mutation in the USH2A gene: association with recessive retinitis pigmentosa without hearing loss. Am J Hum Genet 2000;66:1975-1978.

-22 Liu X, Tang Z, Li C, Yang K, Gan G, Zhang Z, Liu J, Jiang F, Wang Q Liu M: Novel USH2A compound heterozygous mutations cause RP/USH2 in a Chinese family. Mol Vis 2010;16:454-461.

-23 Wu L, Sun Y, Hu YJ, Yang Y, Yao LL, Zhou XX, Wang H, Zhang R, Huang X, Kong WJ: Increased p66Shc in the inner ear of D-galactose-induced aging mice with accumulation of mitochondrial DNA 3873-bp deletion: P66Shc and mtDNA damage in the inner ear during aging. PLoS ONE 2012; 7:e50483.

-24 Borkholder DA, Zhu X, Frisina RD: Round window membrane intracochlear drug delivery enhanced by induced advection. J Control Release 2014;174:171-176.

-25 Fu X, Zhang L, Jin Y, Sun X, Zhang A, Wen Z, Zhou Y, Xia M, Gao J: Loss of myh14 increases susceptibility to Noise-Induced hearing loss in CBA/CaJ mice. Neural Plast 2016;2016:6720420.

-26 Vasilyeva ON, Frisina ST, Zhu X, Walton JP, Frisina RD: Interactions of hearing loss and diabetes mellitus in the middle age CBA/CaJ mouse model of presbycusis. Hear Res 2009;249:44-53.

27 Yan W, Yao L, Liu W, Sun K, Zhang Z, Zhang L: A kind of rd1 mouse in C57BL/6J mice from crossing with a mutated Kunming mouse. Gene 2017;607:9-15.

28 McCulloch DL, Marmor MF, Brigell MG, Hamilton R, Holder GE, Tzekov R, Bach M: ISCEV standard for fullfield clinical electroretinography (2015 update). Doc Ophthalmol 2015;130:1-12.

29 Neuhaus C, Eisenberger T, Decker C, Nagl S, Blank C, Pfister M, Kennerknecht I, Muller-Hofstede C, Charbel IP, Heller R, Beck B, Ruther K, Mitter D, Rohrschneider K, Steinhauer U, Korbmacher HM, Huhle D, Elsayed SM, Taha HM, Baig SM, Stohr H, Preising M, Markus S, Moeller F, Lorenz B, Nagel-Wolfrum K, Khan AO, Bolz $\mathrm{HJ}$ : Next-generation sequencing reveals the mutational landscape of clinically diagnosed Usher syndrome: copy number variations, phenocopies, a predominant target for translational read-through, and PEX26 mutated in Heimler syndrome. Mol Genet Genomic Med 2017;5:531-552.

-30 Vijayakumar S, Depreux FF, Jodelka FM, Lentz JJ, Rigo F, Jones TA, Hastings ML: Rescue of peripheral vestibular function in Usher syndrome mice using a splice-switching antisense oligonucleotide. Hum Mol Genet 2017

-31 Zou J, Zheng T, Ren C, Askew C, Liu XP, Pan B, Holt JR, Wang Y, Yang J: Deletion of PDZD7 disrupts the Usher syndrome type 2 protein complex in cochlear hair cells and causes hearing loss in mice. Hum Mol Genet 2014;23:2374-2390.

-32 Elbaz H, Besgen V, Rechberger K, Sekundo W, Apfelstedt-Sylla E: Electroretinogram and visual field changes in a case of birdshot chorioretinopathy. Doc Ophthalmol 2017;134:149-153.

33 Vesseur A, Free R, Snels C, Dekker F, Mylanus E, Verbist B, Frijns J: Hearing restoration in cochlear nerve deficiency: the choice between cochlear implant or auditory brainstem implant, a meta-analysis. Otol Neurotol 2018;39:428-437.

34 Bateman JB, Klisak I, Kojis T, Mohandas T, Sparkes RS, Li TS, Applebury ML, Bowes C, Farber DB: Assignment of the beta-subunit of rod photoreceptor cGMP phosphodiesterase gene PDEB (homolog of the mouse rd gene) to human chromosome 4p16. Genomics 1992;12:601-603.

-35 Kang K, Tarchick MJ, Yu X, Beight C, Bu P, Yu M: Carnosic acid slows photoreceptor degeneration in the 


\section{Cellular Physiology Cell Physiol Biochem 2018;47:1883-1897

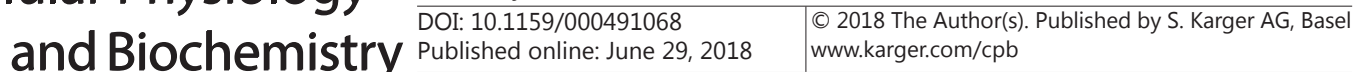

Pde6b(rd10) mouse model of retinitis pigmentosa. Sci Rep 2016;6:22632.

-36 Danciger M, Blaney J, Gao YQ, Zhao DY, Heckenlively JR, Jacobson SG, Farber DB: Mutations in the PDE6B gene in autosomal recessive retinitis pigmentosa. Genomics 1995;30:1-7.

-37 Cheng LL, Han RY, Yang FY, Yu XP, Xu JL, Min QJ, Tian J, Ge XL, Zheng SS, Lin YW, Zheng YH, Qu J, Gu F: Novel mutations in PDE6B causing human retinitis pigmentosa. Int J Ophthalmol 2016;9:1094-1099.

-38 Li Z, Zeng Y, Chen X, Li Q Wu W, Xue L, Xu H, Yin ZQ: Neural stem cells transplanted to the subretinal space of rd1 mice delay retinal degeneration by suppressing microglia activation. Cytotherapy 2016;18:771-784.

-39 Testa F, Melillo P, Bonnet C, Marcelli V, de Benedictis A, Colucci R, Gallo B, Kurtenbach A, Rossi S, Marciano E, Auricchio A, Petit C, Zrenner E, Simonelli F: Clinical presentation and disease course of Usher syndrome because of mutations in myo7a or ush2a. Retina 2017;37:1581-1590.

40 Liu X, Bulgakov OV, Darrow KN, Pawlyk B, Adamian M, Liberman MC, Li T: Usherin is required for maintenance of retinal photoreceptors and normal development of cochlear hair cells. Proc Natl Acad Sci U S A 2007;104:4413-4418.

41 Hentze MW, Kulozik AE: A perfect message: RNA surveillance and nonsense-mediated decay. Cell 1999;96:307-310.

42 Mitton KP, Guzman AE, Deshpande M, Byrd D, DeLooff C, Mkoyan K, Zlojutro P, Wallace A, Metcalf B, Laux K, Sotzen J, Tran T: Different effects of valproic acid on photoreceptor loss in Rd1 and Rd10 retinal degeneration mice. Mol Vis 2014;20:1527-1544.

43 McDonald CM, Campbell C, Torricelli RE, Finkel RS, Flanigan KM, Goemans N, Heydemann P, Kaminska A, Kirschner J, Muntoni F, Osorio AN, Schara U, Sejersen T, Shieh PB, Sweeney HL, Topaloglu H, Tulinius M, Vilchez JJ, Voit T, Wong B, Elfring G, Kroger H, Luo X, McIntosh J, Ong T, Riebling P, Souza M, Spiegel RJ, Peltz SW, Mercuri E: Ataluren in patients with nonsense mutation Duchenne muscular dystrophy (ACT DMD): a multicentre, randomised, double-blind, placebo-controlled, phase 3 trial. Lancet 2017;390:1489-1498.

-44 Johnson KR, Zheng QY, Weston MD, Ptacek LJ, Noben-Trauth K: The Mass1frings mutation underlies early onset hearing impairment in BUB/BnJ mice, a model for the auditory pathology of Usher syndrome IIC. Genomics 2005;85:582-590.

45 McGee J, Goodyear RJ, McMillan DR, Stauffer EA, Holt JR, Locke KG, Birch DG, Legan PK, White PC, Walsh EJ, Richardson GP: The very large G-protein-coupled receptor VLGR1: a component of the ankle link complex required for the normal development of auditory hair bundles. J Neurosci 2006;26:6543-6553.

-46 Weston MD, Luijendijk MW, Humphrey KD, Moller C, Kimberling WJ: Mutations in the VLGR1 gene implicate G-protein signaling in the pathogenesis of Usher syndrome type II. Am J Hum Genet 2004;74:357-366.

-47 Hilgert N, Kahrizi K, Dieltjens N, Bazazzadegan N, Najmabadi H, Smith RJ, Van Camp G: A large deletion in GPR98 causes type IIC Usher syndrome in male and female members of an Iranian family. J Med Genet 2009;46:272-276.

48 Schwartz SB, Aleman TS, Cideciyan AV, Windsor EA, Sumaroka A, Roman AJ, Rane T, Smilko EE, Bennett J, Stone EM, Kimberling WJ, Liu XZ, Jacobson SG: Disease expression in Usher syndrome caused by VLGR1 gene mutation (USH2C) and comparison with USH2A phenotype. Invest Ophthalmol Vis Sci 2005;46:734743.

49 Skradski SL, Clark AM, Jiang H, White HS, Fu YH, Ptacek LJ: A novel gene causing a mendelian audiogenic mouse epilepsy. Neuron 2001;31:537-544.

50 Libby RT, Steel KP: Electroretinographic anomalies in mice with mutations in Myo7a, the gene involved in human Usher syndrome type 1B. Invest Ophthalmol Vis Sci 2001;42:770-778.

51 Mehalow AK, Kameya S, Smith RS, Hawes NL, Denegre JM, Young JA, Bechtold L, Haider NB, Tepass U, Heckenlively JR, Chang B, Naggert JK, Nishina PM: CRB1 is essential for external limiting membrane integrity and photoreceptor morphogenesis in the mammalian retina. Hum Mol Genet 2003;12:21792189.

52 Hmani-Aifa M, Benzina Z, Zulfiqar F, Dhouib H, Shahzadi A, Ghorbel A, Rebai A, Soderkvist P, Riazuddin S, Kimberling WJ, Ayadi H: Identification of two new mutations in the GPR98 and the PDE6B genes segregating in a Tunisian family. Eur J Hum Genet 2009;17:474-482. 